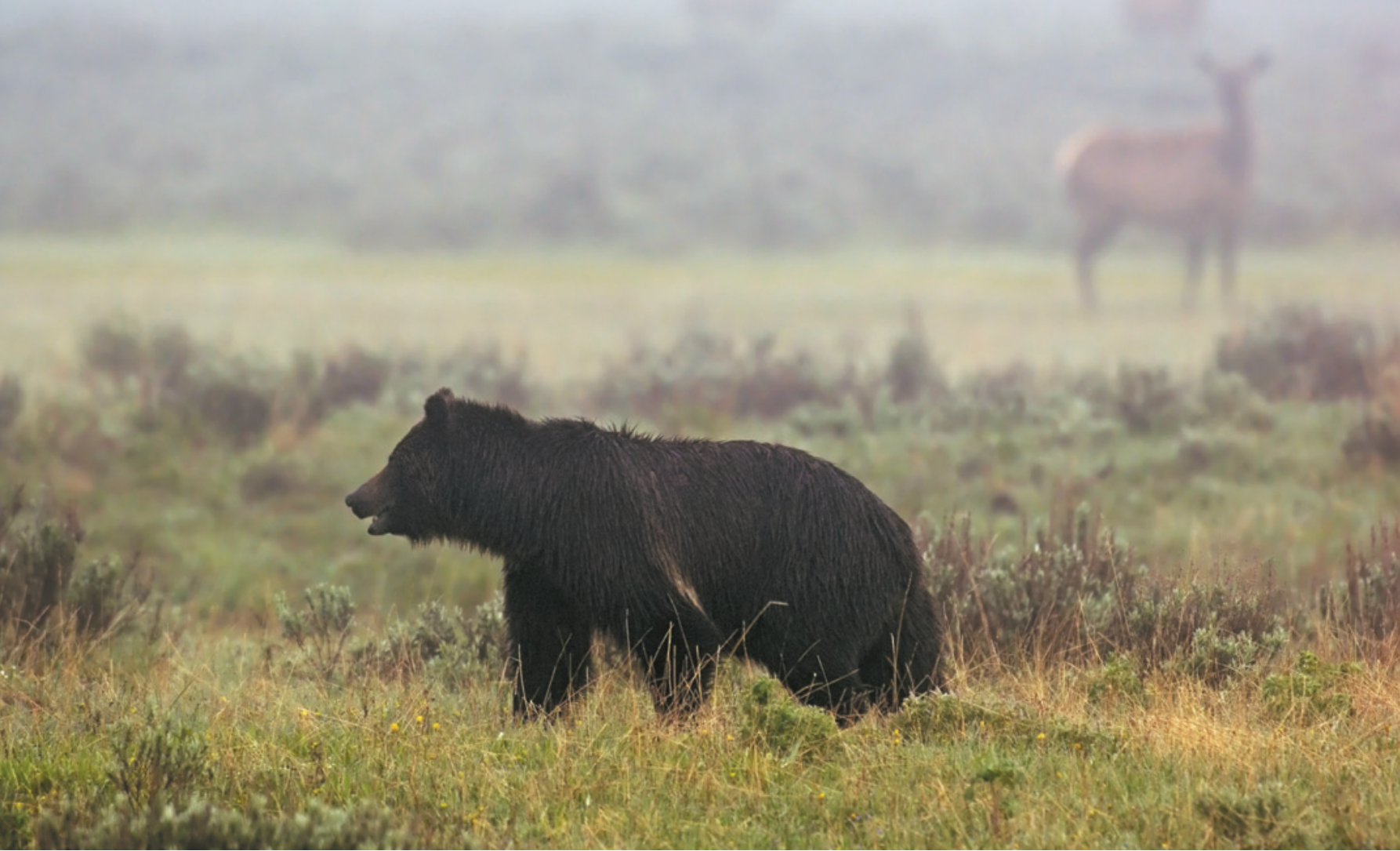

Grizzly bears in Yellowstone National Park are switching from eating pine nuts to eating meat as global warming has allowed pests to kill pine trees.

ECOLOGY

\title{
Yellowstone grizzlies face losing protected status
}

\section{Conservationists protest after panel recommends ending bears' endangered-species listing.}

\section{BY LAUREN MORELLO}

$\mathrm{F}$

or the US government, the grizzly bears of Yellowstone National Park in Wyo-

ming embody a stunning success story: a population resurgent after 40 years of protec-

tion under the Endangered Species Act. More

than 700 bears now roam the region, up from

136 in 1975, when the grizzly (Ursos arctos horribilis) was listed as threatened after decades of deadly clashes with ranchers, hunters and park visitors. But the US Fish and Wildlife Service is now expected to lift the legal safeguards, after a government advisory panel of wildlife officials endorsed delisting the bear last month.

Conservation groups have pushed back, saying that the government has underestimated the threat that climate change poses to the bears' food supply, especially stands of whitebark pine. As the Yellowstone region has warmed, mountain pine beetles and blister rust fungus - once thwarted by the cold, dry climate - have devastated the trees, depriving grizzlies of energy-rich pine nuts. Moreover, say conservationists, invasive fish have crowded out native cutthroat trout in Yellowstone Lake at the heart of the park, reducing another important food source for the bears.

"We have an unprecedented situation with deteriorating foods, and an ecosystem that is

\section{HOME ON THE RANGE}

A growing Yellowstone grizzly-bear population now extends beyond the national park.

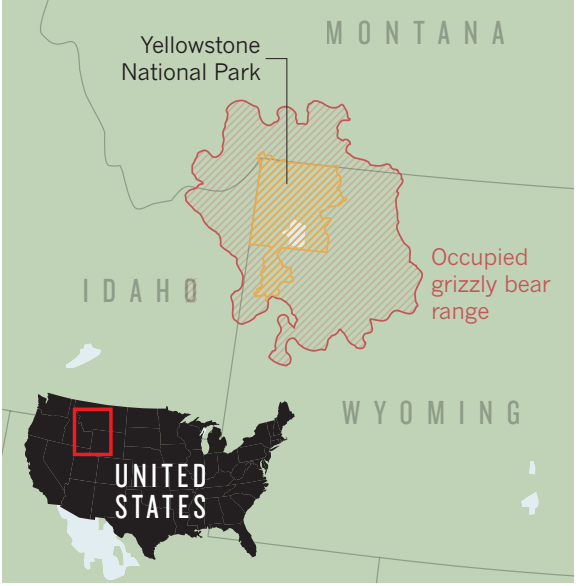

unravelling," says Louisa Willcox, the Northern Rockies representative at the Center for Biological Diversity in Livingston, Montana. The centre was one of several groups that sued the US government in 2007, following an earlier attempt to delist the bear. After two years, a district-court judge restored protection, citing concerns about the declining whitebark pine and its effect on the bears' diet.

A report delivered in November by the US Geological Survey’s Interagency Grizzly Bear Study Team describes a resilient and healthy bear population that has adapted to the loss of pine nuts by eating more elk and bison, keeping fat stores at levels that allow the bears to survive and reproduce. For Christopher Servheen, a biologist who oversees grizzly-bear recovery efforts at the Fish and Wildlife Service in Missoula, Montana, that is not surprising. "Bears are flexible," he says. "It's easier to say what they don't eat than what they do eat."

But other researchers suspect that the change carries a steep price. "Eating meat is hazardous on all fronts," says David Mattson, an ecologist at Yale University in New Haven, Connecticut. A reliance on meat heightens 
the risk that adult bears will come into contact with humans, including livestock owners and hunters seeking elk, he says. For young bears, it may increase the frequency of potentially deadly interactions with aggressive adult male bears and wolves.

Critics also argue that the government is basing its decisions on flawed population estimates. A study published last July suggests that the government's figure of 741 bears is inflated (D. F. Doak and K. Cutler Conserv. Lett. http://doi.org/q3d; 2013). The number of survey flights used to count bears has tripled since the mid-1990s, but, the study argues, the model used to extrapolate population figures from the flights' tallies does not account for increased observation time. Further distortion may arise because the model assumes that female bears will reproduce consistently throughout their 30-year lives, with no decrease in fertility as they age.

Mattson says that population estimates have in the past jumped by more than 100 bears when the statistical method has shifted. "There is no clean and simple way to estimate the size and trend of the Yellowstone population," he says.

But those criticisms are rejected by Frank van Manen, a wildlife biologist with the US Geological Survey in Bozeman, Montana, who led the diet study. Observation time has increased, he says, but so has the grizzly bears' range (see 'Home on the range'), which cancels out any observer bias from increased search hours. And although the government's official estimate of the population did jump from 629 to 741 bears this year, van Manen says that the new number is better. That is in part because the revision takes into account a 2011 demographic study of bear survival rates based on radio-collar tracking data - the first such study since 2002 - that gives biologists more confidence in their population surveys.

Servheen says that if the government were to decide to pursue delisting, as many expect, the decision would not be announced until late spring at the earliest. At that point, the Fish and Wildlife Service would open a 60 -day publiccomment period to seek reaction.

But even that is unlikely to be the last word on the grizzlies: conservation groups are already gearing up to sue. Perhaps the only point on which the US government and its opponents agree is that there will be more legal wrangling over the Yellowstone bears' future. "It's sad that it's come to this," says Servheen. "What it should be is a celebration."

\section{Sea drilling project launches}

\section{International expedition hopes to unravel mysteries of the South China Sea, one of the world's most geologically important seas.}

\section{BY JANE QIU}

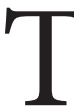
The South China Sea is well known for its geopolitical tensions, but less is known about its many geological stresses and strains. That is set to change.

On 28 January, an international team of scientists - from countries including China, the Philippines, India and the United States - is due to set sail from Hong Kong on board the research vessel JOIDES Resolution, marking the first expedition of the International Ocean Discovery Program (IODP), formerly known as the Integrated Ocean Drilling Program. Its aim is to determine the age of the South China Sea, and to resolve ongoing controversy over how it formed.

With an area of more than 3 million square kilometres and thousands of islands and reefs, the sea occupies a scientifically interesting position between the world's highest mountains, the Himalayas, and the deepest point on Earth's surface, the Mariana Trench in the western Pacific Ocean.

It is "a natural laboratory for studying continent break-ups and sedimentary-basin formation", says Dieter Franke, a geologist at the Federal Institute for Geosciences and Natural Resources in Hannover, Germany, who is not

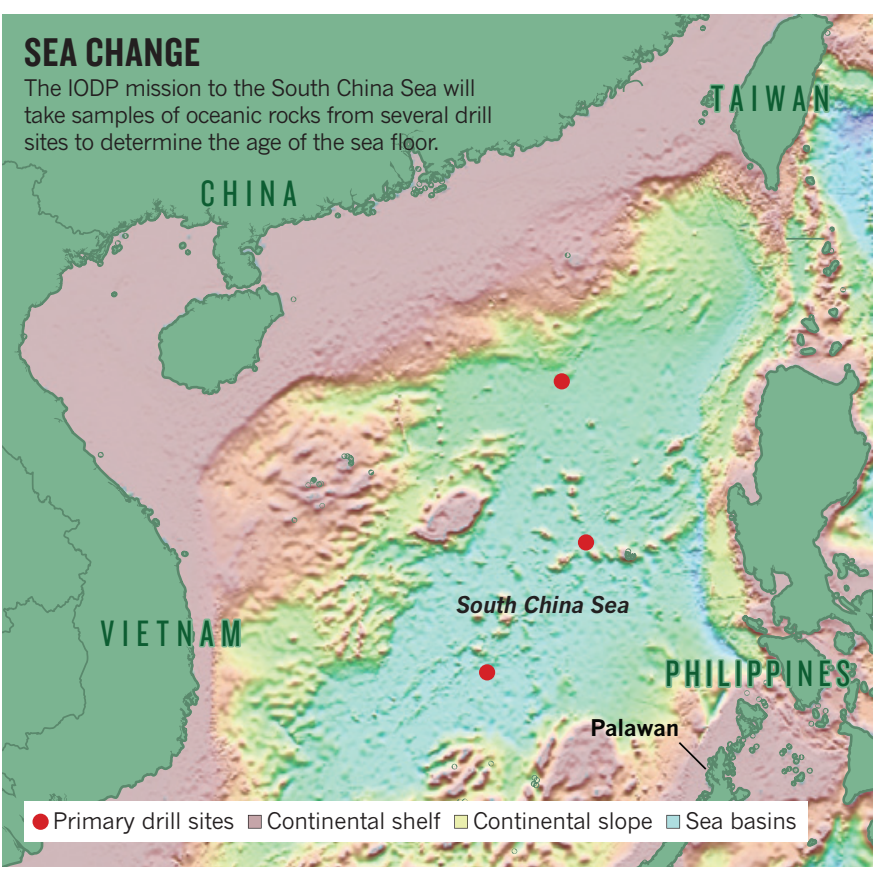

created after a part of Eurasia that once stood in its place began to stretch in a north-south direction. As the stretching continued, the continent became progressively thinner. At some point it broke apart, releasing magma that solidified and moved away from the eruption sites - a process called sea-floor spreading. The land mass drifted south, breaking into pieces and giving rise to islands such as Palawan in the Philippines and Borneo.

But for decades, geologists have been debating what triggered the continent to stretch and break up in the first place. Among the ideas proposed are that it was caused by the collision between Eurasia and the Indian subcontinent; that the continent buckled as an ancient oceanic plate slid beneath presentday southern China; or that the Pacific plate pulled away from

involved in the expedition. The sea's relatively small size and young age (between 25 million and 42 million years old) compared with major ocean basins (the Pacific plate can be traced back at least 200 million years) mean that it is possible to probe its entire history through just a couple of IODP expeditions, Franke says.

Little is known about the formation of the South China Sea. The crust beneath it was

\section{the the Eurasian coast.}

"The hypotheses are based only on circumstantial evidence," says Jian Lin, a marine geophysicist at the Woods Hole Oceanographic Institution in Massachusetts and co-chief scientist on the drilling project. "Much of the controversy stems from different estimates of how old the sea floor is." Until recently, scientists have had to make age estimates by towing 